\title{
Energy Efficient Ship Operation through Speed Optimisation in Various Weather Conditions
}

\author{
Tong Cui, Benjamin Howett, Mingyu Kim, Ruihua Lu, Yigit Kemal Demirel, \\ Osman Turan, Sandy Day and Atilla Incecik \\ Department of Naval Architecture, Ocean and Marine Engineering, \\ University of Strathclyde, \\ 100 Montrose Street, Glasgow G4 0LZ, UK, tong.cui@strath.ac.uk
}

\begin{abstract}
Speed optimisation or speed management has been an attractive topic in the shipping industry for a long time. Traditional methods just rely on master's experience. Some recent methods are more efficient but always have many constraints, which cannot get optimum speed profile. This paper introduces a relatively advanced model for speed global optimisation towards energy efficient shipping in various weather conditions and shows the effect when the method is employed. With this model, if a ship type, departure and destination ports and fixed ETA (Estimated Time Arrival) are given, the stakeholders can be provided with a more reasonable speed operation plan for a certain commercial route, which leads to lower fuel consumption. Weather conditions and hence routing plays a very important role in this process. Several case studies over different shipping conditions are considered to validate the model.
\end{abstract}

\section{Keywor ds}

Speed optimisation · Weather routing · Energy efficiency

\section{Introduction}

Shipping plays an important role in the global economy, as almost $90 \%$ goods traded worldwide are transported by sea. The Greenhouse Gas (GHG) emissions and the energy consumption from shipping field are significant, which have become very important factors that can not be ignored for both environment and economic benefit (IMO 2014; IHS Global Insight 2009; Oxford Economics 2014). The modern shipping industry is paying more and more attention to energy saving and emission reduction. In recent years, as the main regulatory body for shipping, the International Mar itime Organisation (IMO) has raised several technical and operational measures towards regulating shipping energy efficiency and thereby controlling the marine GHG emissions. One of the most important concepts is Ship Energy Efficiency Management Plan (SEEMP).

Ship Energy Efficiency Management Plan is designed to provide the framework, against which, a ship owner can develop best practice and energy efficient operations. 
The IMO introduced the SEEMP as a mandatory tool under MARPOL Annex VI ${ }^{1}$ and entered into force on January 1, 2013.

There are many categories of energy improvement methods for potential adoption within each ship's SEEMP, including Fuel-efficient Sh ip Operations, Optimised Ship Handling, Hull Maintenance, Propulsion System, Waste Heat Recovery etc. For the category of Fuel-efficient ship operations recommended by SEEMP (IMO 2012), it includes:

- Improved voyage planning

- Weather routing

- Just in time

- Speed optimisation

- Optimized shaft power

Among them, speed optimisation and weather routing are two very common and effective approaches for energy efficient ship operations (IMO 2012, 2016; Simonsen et al 2015).

Speed optimisation means to select an optimum speed changing strategy for a given route, which can make a great contribution to energy efficient shipping. There are many types of research in this field. Several studies assumed the ship speed is fixed (Wang et al 2011,2012), while several studies also make a speed up or reduction with a certain speed step to see the benefits (Norstad et al 2011; Lu et al 2014). Several studies carried out the speed optimisation based on Historical data and Sea current forecasts (Jussi 2012). Heuristic methods, like genetic, is also used for speed optimisation by Golias et al. (2010), but the optimality cannot be guaranteed. Besides, several studies created the relationship model between fuel consumption and sailing speed (Lang and Veenstra 2010; Du et al. 2011) or even between oil price and sailing speed (D Ronen 2011) for energy efficient shipping. All of these studies provide very positive methods but still cannot avoid having more or fewer constraints, especially not able to provide accurate ship operations with various weather conditions.

Actually, weather condition is a very important factor, which can not be ignored during speed optimisation. When combined with weather routing technique, the speed optimisation will become more reliable. Ship weather routing is used to determine the optimum route (course and speed) between given departure and destination ports based on weather conditions and ship's corresponding performance. It always aims to minimum fuel consumption, suitable ETA (estimated time arrival) or maximum ship safety etc. It has been proven as a very effective tool in shipping field (Simonsen 2015; Chen 1998; Buhaug 2009).

In this paper, a speed optimisation model is developed for energy efficient shipping. This model is composed of several sub-modules, including ship performance calcula-

\footnotetext{
${ }^{1}$ MARPOL: International Convention for the Prevention of Pollution from Ships Annex VI: Prevention of air pollution by ships
} 
tion module, grids system design module, weather routing module, etc. Every module has its own task, and every one of them should link with each other so that the whole model can run well towards energy efficient shipping. With the weather routing module integrated, this model can predict ship operations in various sea states well. Besides, it can also combine with any other technologies very well, like wind assistant, fouling influence prediction etc. Therefore, with so many factors into consideration, this model will certainly provide stakeholders more reliable ship operations for a shipping task.

\section{Speed Optimisation Model}

The Speed Optimisation Model presented in this paper is not only for single fixed route optimisation but also for global optimisation which also takes the direction optimisation into consideration. According to the requirement from stakeholders, the only input items are the ship model, departure time and ETA, positions of departure and destination, and then the model will determine an optimum route towards min $i$ mum fuel consumption after complicated calculation.

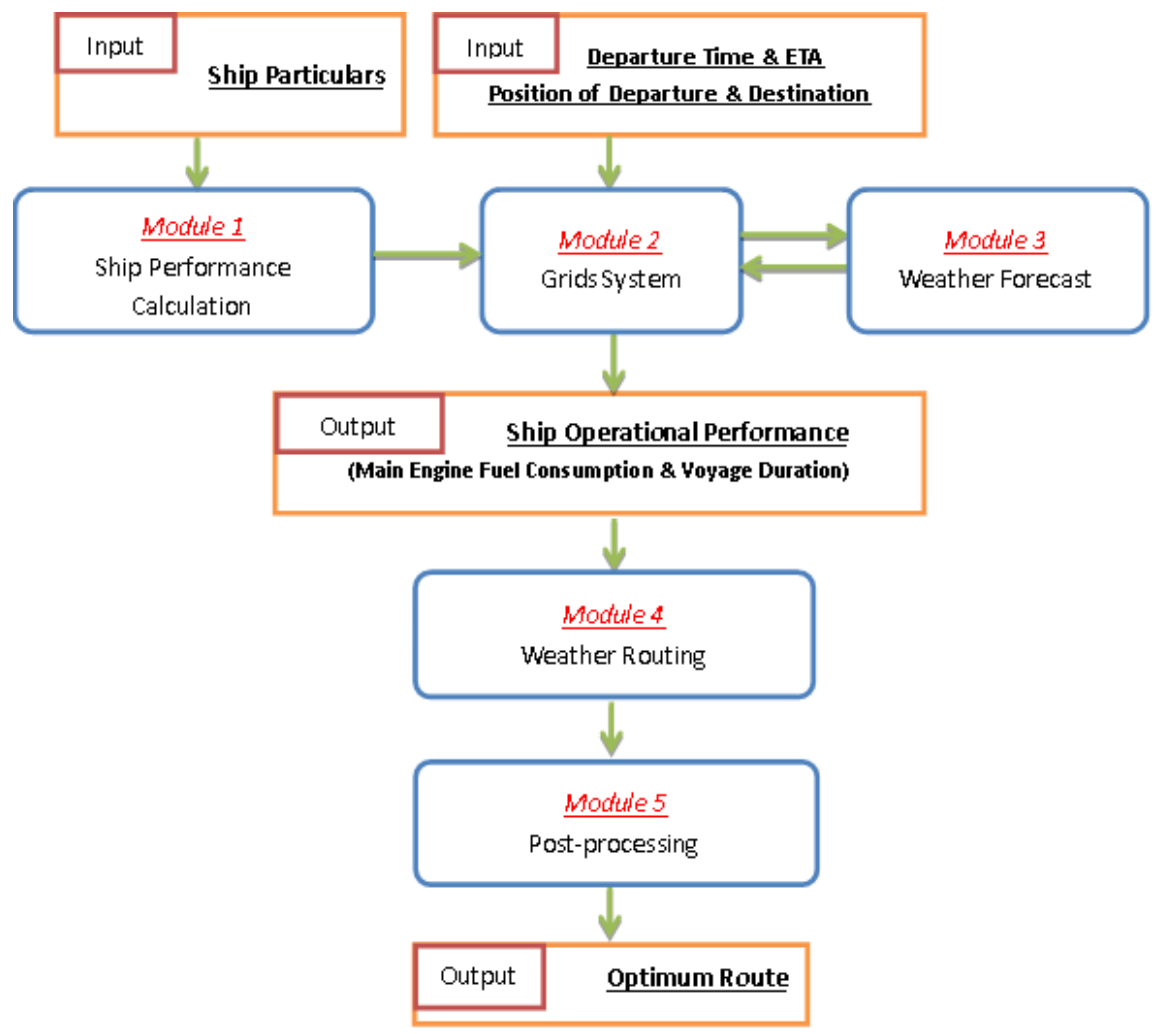

Fig. 1 Workflow of Speed Optimisation Model 
The workflow of the model is shown in Fig.1. It can be seen the model generally contains five modules, and each of them will be introduced briefly as below:

\subsection{Module 1: Ship Performance Calculation}

Since the speed optimisation model runs towards minimum fuel consumption under various weather conditions, the ship performance prediction becomes a very important module of the whole model, which should predict ship brake power under different situations very accurately. In this module, the ship particulars including ship geometry, main engine and propeller parameters should be collected firstly. Next, the ship resistance in calm water can be predicted based on Holtrop 84 method (Holtrop 1984) while the added resistance due to waves and wind can be calculated based on the Kwon's method (Kwon 2008) a fter weather forecast module is introduced. Based on the total resistance, together with ship speed, propeller open water performance and efficiency of transmission of power, the ship engine brake power can be determined, which is necessary for fuel consumption calculation. Besides, the sea trial data, ship model test data or even noon report data can be introduced to verify the predicted ship performance. Based above, when weather data is given, the ship performance in this sea state can be obtained in this module, which will be us ed in weather routing module afterward.

In order to obtain ship performance very quickly and conveniently, once ship particulars are decided, a ship performance database can be generated before running the whole speed optimisation model. With the given variable (sailing speed, weather data etc), the ship performance can be easily determined through the database. One simple database contains these dimensions: speed, significant wave height, relative wave angle, true wind speed, relative wind angle and an output attribute: brake power (Howett 2015). The ship performance database may also include additional dimensions (eg draft/loading condition) or additional attributes (eg fuel consumption) where required. Therefore, when alternative energy saving techniques or other influencing factors are taken into account, the model only needs to generate a new ship performance database without changing anything else. This makes the speed optimisation model combine with other external techniques well.

\subsection{Module 2: Grids system}

Grids system means the waypoints distribution strategy in the shipping area. The ship will travel along the potential route formed by these waypoints. In this grids system, as presented in Fig.2, great circle route (The shortest distance between two points on a sphere) is taken as the reference route, which is divided into several equal stages with certain numbers of nodes. Through every point, a straight line can be drawn perpendicular to its tangent line around the circle. Next, certain numbers of nodes can be distributed along this vertical line, including upper and lower parts of the great circle. The ship in one stage can travel to any waypoint in next stage. Here, considering the larger course deviations are not feasible and would be unrealistic for an opt imum route, a limit is set for the ship in one waypoint, which can only go to nearest 
five waypoints in next stage. For some special shipping tasks, such as the ship going to several fixed ports during the whole navigation, the grids system can be automatically divided into several stages based on the same principle. Besides, for most real situations, the ship always travels around some is lands or avoid the prohibited military zone, an area avoidance function is also developed.

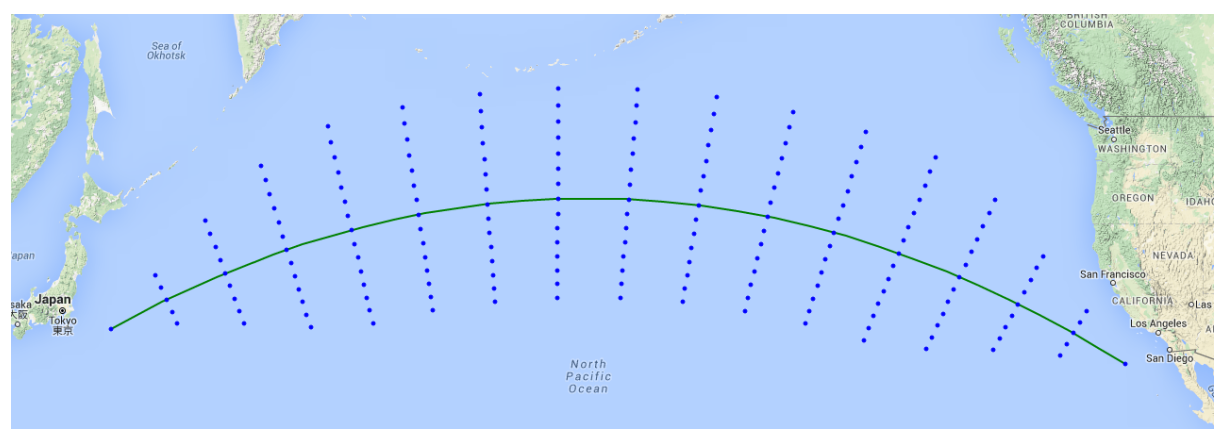

Fig. 2 A Typical Grids system

It is worth noting that the speed optimisation for a single fixed route (without direction optimisation) can be regarded as a special but much easier situation within the normal global optimisation. For a fixed route, it must be formed by several certain waypoints as well. The latitude and longitude of every certain waypoint will be input to grids system manually. So that the grids system also has several stages but has only one waypoint, thus, one direction on each stage. The whole speed optimisation will carry out with this simple grids system.

\subsection{Module 3: Weather Forecast}

This system will take only winds, waves into account at the moment. Waves and winds data are both downloaded from ECMWF (European Centre for Med ium-Range Weather Forecasts) website. The data is constructed in gridded binary (GRIB) data form, including 10 meter $\mathrm{U}$ wind component, 10 meter $\mathrm{V}$ wind component, mean wave direction, mean wave period and significant height of co mb ined wind waves and swell, and they all update every 6 hours. These weather data will be converted to Beaufort Number and relative weather direction according to ship heading for ship performance calculation. The weather forecast files are linked with three common parameters: time, latitude and longitude. With given time, latitude and longitude, the weather forecast module will provide corresponding sea conditions to grids system.

\subsection{Module 4: Weather Routing}

Weather routing module is the core of the whole speed optimisation model. The global optimization strategy is introduced in this module. 


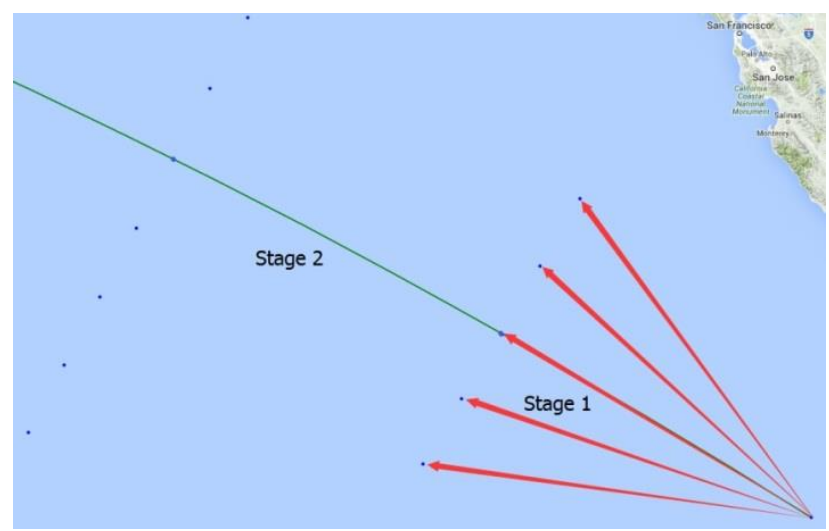

Fig. 3 Ship routing stages

As mentioned in Module 2, the ship will travel from the departure to destination stage by stage (Fig. 3). For the ship in any waypoint, the system reads the weather data at that point in accordance with local longitude, latitude and departure time firstly. Next, a random speed is assigned to a travel direction. This speed ranges from minimum speed to maximum speed with an interval speed. Having the weather data and ship speed, according to ship performance calculation result, the fuel consumption on this arc is calculated under this speed and direction. Then the navigation information of this arc (fuel consumption, ship speed, navigation duration, local time and coordinates of local departure point) is stored in its arrival point. After that, the ship will travel to next waypoint based on all information saved in this arrival point.

The whole calculation starts from the departure port. Under this simulation principal as described above, the fuel consumption modeling will be continuously utilised for all stages between departure port and destination. This process covers all the speed and direction options. In the end, the total fuel consumption and voyage duration of the different potential route with different speed set will be stored in the destination node. The recorded information will be used to select the minimum fuel consumption route at given ETA, which is regarded as the global optimisation. During the optimisation process, several smart algorithms are added to the weather routing module, which can reduce much calculation time and make the whole calculation run towards the required ETA faster.

\subsection{Module 5: Post-processing}

After the calculation in weather routing module is finished, there will be many results stored in final destination waypoint. This module will select the minimum fuel consumption route under required ETA for stakeholders. According to the information stored in every waypoint on this route, the speed, duration, fuel consumption and weather data etc. of every stage will be extracted in detail. Users can see and handle them very easily. 


\section{Case studies}

A Bulk Carrier with 35,500DWT and 175.72 meters in length is taken as the ship model in the case studies. The shipping area is from Dubai to the middle of the Indian Ocean, but the ship should travel along the west end of India. The departure and destination points are given as $25^{\circ} 15^{\prime} \mathrm{N} \backslash 56^{\circ} 51^{\prime} \mathrm{E}$ and $8^{\circ} 13^{\prime} \mathrm{S} \backslash 92^{\circ} 22^{\prime} \mathrm{E}$ respectively. The grids system has 19 stages, and every stage has maximum 15 vertical waypoints with equal distance of 30 nautical miles. Sh ip speed ranges from minimum 9 knots to maximum 19 knots with the interval speed 0.1 knot. The required ETA is set at 242 hours.

\subsection{Case Study 1}

In order to see the benefits of the model, the speed sets under six different conditions are selected for comparison, which are shown as below:

Speed Set A - Actual route and actual voyage speed as recorded in ship noon report Speed Set B - Actual route and optimum speed with identical ETA

Speed Set C - Global Optimisation with identical ETA

Speed Set D - Global Optimisation with 3\% less ETA

Speed Set E - Global Optimisation with 3\% more ETA

Speed Set F - Global Optimisation with 5\% more ETA

Global optimisation means optimise both speed and direction at the same time. So the resulting route may be different from the actual route recorded in ship noon report. All of above have same departure time at 2015-05-13, 23:00. The results are shown in Table 1.

As can be seen from Table 1, compared to Speed Set A, the speed optimisation (Speed Set B) for a fixed route will provide $1.47 \%$ fuel savings, while global optimisation (Speed Set C, both speed and direction optimisation) can provide $1.60 \%$ fuel savings. For Speed Set D, because it has 3\% shorter ETA, the average sailing speed will increase, so it will consume $4.43 \%$ more fuels. As to Speed Set E with 3\% longer ETA and Speed Set F with 5\% longer ETA, based on the same reason, they will respectively provide $7.05 \%$ and $10.2 \%$ fuel savings.

The speed, BN (Beaufort number, which reflects wind force and significant wave height) and relative weather direction in each stage of Speed Set $C$ are extracted in Fig. 4. To compare more clearly, the speed unit has been changed from knots to $\mathrm{m} / \mathrm{s}$. It can be seen that the ship speed has very good response to different weather conditions. When $\mathrm{BN}$ is increasing, the ship will reduce speed and will speed up again when the $\mathrm{BN}$ is low. The impact factor of $\mathrm{BN}$ is also higher than relative weather directions. At stage 16 to 19 , although the ship travels in head sea or bow sea (relative weather direction from $0^{\circ}$ to $60^{\circ}$ ), because the $\mathrm{BN}$ is relatively low, the ship can still travel at relatively higher speed. All of these routes are drawn on the map in Fig. 5. 
Table 1. Comparison of ship operational performance of different speed sets for case study 1

\begin{tabular}{|c|c|c|c|c|c|c|}
\hline Stage & $\begin{array}{c}\text { Speed } \\
\text { Set A } \\
\text { (knots) }\end{array}$ & $\begin{array}{l}\text { Speed } \\
\text { Set B } \\
\text { (knots) }\end{array}$ & $\begin{array}{l}\text { Speed } \\
\text { Set C } \\
\text { (knots) }\end{array}$ & $\begin{array}{l}\text { Speed } \\
\text { Set D } \\
\text { (knots) }\end{array}$ & $\begin{array}{c}\text { Speed } \\
\text { Set E } \\
\text { (knots) }\end{array}$ & $\begin{array}{c}\text { Speed } \\
\text { Set F } \\
\text { (knots) }\end{array}$ \\
\hline 1 & 12.5 & 12.8 & 13.0 & 13.0 & 13.2 & 12.8 \\
\hline 2 & 12.5 & 13.2 & 13.2 & 13.2 & 12.6 & 13.2 \\
\hline 3 & 12.7 & 12.6 & 13.0 & 13.0 & 12.6 & 12.6 \\
\hline 4 & 12.5 & 12.6 & 13.0 & 12.6 & 9.7 & 12.6 \\
\hline 5 & 12.4 & 10.7 & 10.1 & 11.9 & 12.6 & 9.7 \\
\hline 6 & 13.0 & 12.8 & 12.6 & 12.8 & 11.9 & 12.6 \\
\hline 7 & 12.8 & 12.1 & 12.1 & 12.1 & 12.1 & 11.9 \\
\hline 8 & 12.6 & 12.6 & 12.6 & 13.0 & 12.6 & 11.9 \\
\hline 9 & 12.4 & 13.6 & 12.6 & 13.0 & 12.1 & 12.6 \\
\hline 10 & 12.1 & 13.0 & 12.1 & 13.0 & 11.9 & 11.9 \\
\hline 11 & 13.2 & 12.6 & 13.4 & 13.4 & 12.6 & 11.9 \\
\hline 12 & 12.5 & 13.0 & 12.6 & 13.2 & 12.1 & 12.6 \\
\hline 13 & 12.4 & 9.7 & 12.1 & 12.6 & 9.7 & 9.7 \\
\hline 14 & 12.3 & 12.1 & 11.3 & 12.1 & 11.9 & 9.7 \\
\hline 15 & 13.1 & 12.1 & 12.1 & 12.2 & 12.6 & 11.9 \\
\hline 16 & 12.9 & 12.6 & 12.6 & 12.6 & 13.2 & 12.6 \\
\hline 17 & 12.4 & 12.8 & 13.2 & 13.2 & 13.4 & 13.2 \\
\hline 18 & 11.9 & 13.2 & 13.0 & 13.2 & 13.2 & 13.2 \\
\hline 19 & 11.8 & 12.8 & 13.2 & 13.4 & 13.2 & 13.2 \\
\hline $\begin{array}{l}\text { Voyage } \\
\text { Duration } \\
\text { (hours) }\end{array}$ & 242 & 242 & 242 & 235 & 249 & 254 \\
\hline $\begin{array}{c}\text { Fuel } \\
\text { Consumption } \\
\text { (tonnes) }\end{array}$ & 135.23 & 133.24 & 133.06 & 141.23 & 125.69 & 121.37 \\
\hline $\begin{array}{c}\text { Fuel Savings } \\
\text { compared to Speed } \\
\text { Set A (\%) }\end{array}$ & 0 & 1.47 & 1.60 & -4.43 & 7.05 & 10.2 \\
\hline
\end{tabular}




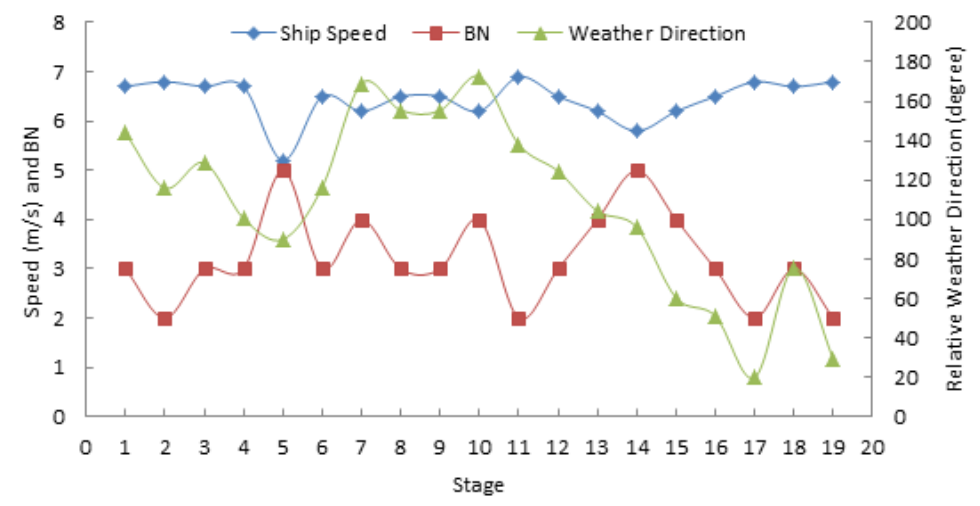

Fig. 4 The speed and weather condition distribution of Speed Set C

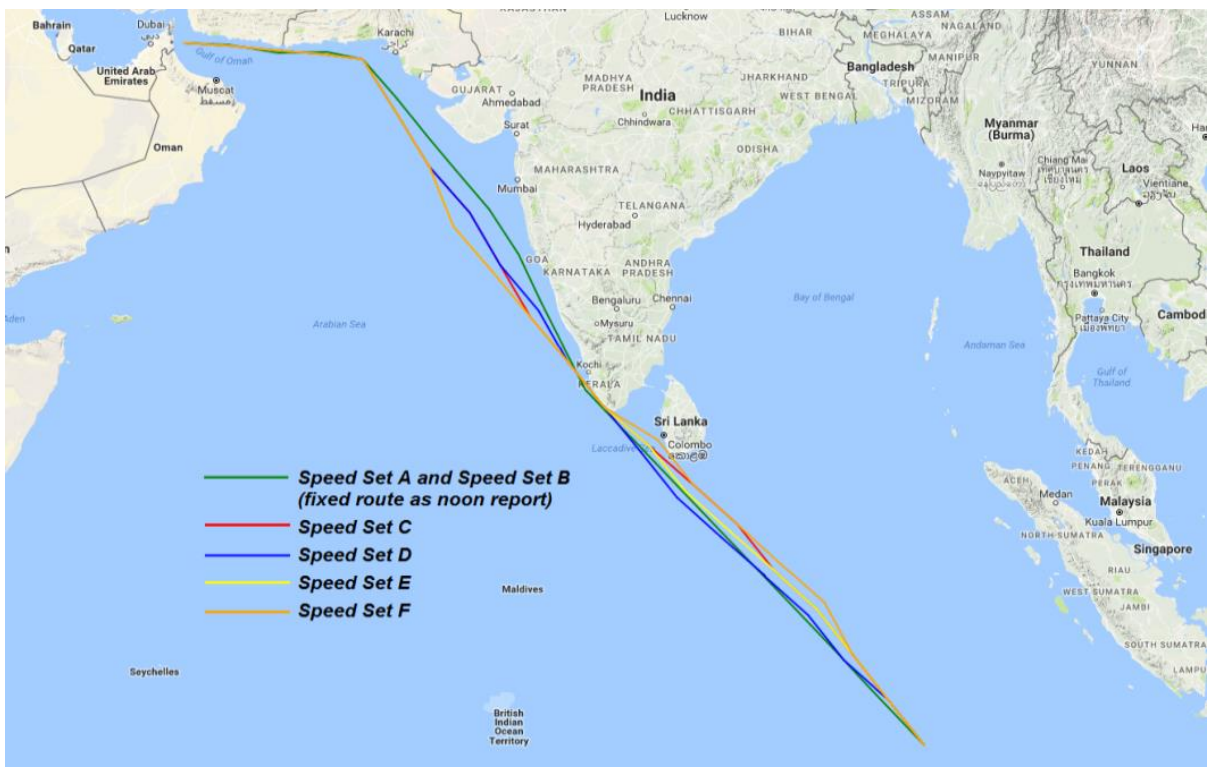

Fig.5 Optimal routes based on different conditions for case study 1

\subsection{Case Study 2}

In order to see the speed optimisation benefits under various weather condition more clearly, another three case studies departure at different seasons are carried out. Together with the Speed Set C, they are list as below:

Speed Set G - Global Optimisation with the departure time of 2015-02-13， 23:00 Speed Set C - Global Optimisation with the departure time of 2015-05-13, 23:00 Speed Set H - Global Optimisation with the departure time of 2015-08-13, 23:00 Speed Set I - Global Optimisation with the departure time of 2015-11-13, 23:00 
Above simulations have different departure seasons at February, May, August and November, but have same ETA of 242 hours. The results are shown in Table 2.

Table 2. Comparison of ship operational performance of different speed sets for case study 2

\begin{tabular}{|c|c|c|c|c|}
\hline Stage & $\begin{array}{c}\text { Speed Set G } \\
\text { Feb } \\
(\text { knots })\end{array}$ & $\begin{array}{c}\text { Speed Set C } \\
\text { May } \\
\text { (knots) } \\
\end{array}$ & $\begin{array}{c}\text { Speed Set H } \\
\text { Aug } \\
(\text { knots })\end{array}$ & $\begin{array}{c}\text { Speed Set I } \\
\text { Nov } \\
\text { (knots) }\end{array}$ \\
\hline 1 & 13.2 & 13.0 & 13.2 & 12.6 \\
\hline 2 & 13.0 & 13.2 & 13.2 & 11.9 \\
\hline 3 & 11.9 & 13.0 & 12.6 & 11.9 \\
\hline 4 & 11.9 & 13.0 & 13.2 & 11.9 \\
\hline 5 & 11.9 & 10.1 & 12.1 & 13.2 \\
\hline 6 & 11.9 & 12.6 & 12.1 & 11.9 \\
\hline 7 & 11.9 & 12.1 & 12.6 & 11.9 \\
\hline 8 & 12.6 & 12.6 & 12.4 & 11.9 \\
\hline 9 & 11.9 & 12.6 & 12.6 & 11.9 \\
\hline 10 & 13.2 & 12.1 & 12.6 & 11.9 \\
\hline 11 & 13.2 & 13.4 & 12.6 & 13.2 \\
\hline 12 & 13.2 & 12.6 & 12.6 & 13.2 \\
\hline 13 & 12.6 & 12.1 & 12.1 & 13.4 \\
\hline 14 & 9.7 & 11.3 & 12.1 & 12.6 \\
\hline 15 & 12.6 & 12.1 & 13.2 & 13.2 \\
\hline 16 & 13.2 & 12.6 & 12.6 & 12.6 \\
\hline 17 & 13.4 & 13.2 & 12.2 & 12.6 \\
\hline 18 & 13.2 & 13.0 & 10.9 & 12.6 \\
\hline 19 & 13.2 & 13.2 & 12.2 & 12.6 \\
\hline Average $\mathrm{BN}$ & 3 & 3.21 & 3.32 & 3.05 \\
\hline $\begin{array}{c}\text { Voyage Dura- } \\
\text { tion(hours) }\end{array}$ & 242 & 242 & 242 & 242 \\
\hline $\begin{array}{l}\text { Fuel Consumption } \\
\text { (tonnes) }\end{array}$ & 132.33 & 133.06 & 136.13 & 135.40 \\
\hline $\begin{array}{l}\text { Fuel compared to } \\
\text { Speed Set C (\%) }\end{array}$ & 0.54 & 0 & -2.31 & -1.76 \\
\hline
\end{tabular}

As can be seen from table 2, with different departure seasons, the corresponding fuel consumption will change slightly. Compared with Speed Set C (May), the fuel savings are respectively $0.54 \%$ fewer for Speed Set G (February), 2.31\% more for Speed Set H (August) and 1.76\% mo re for speed Set I (November). Among them, the Speed set I has a different trend, which has relatively lower average $\mathrm{BN}$ but has more fuel consumption comparing to Speed Set C. But after taking relative weather direction 
into consideration, it can be found that Speed Set I has relatively more head sea and bow sea situations, which will definitely add fuel consumption. Therefore, the results are reasonable.

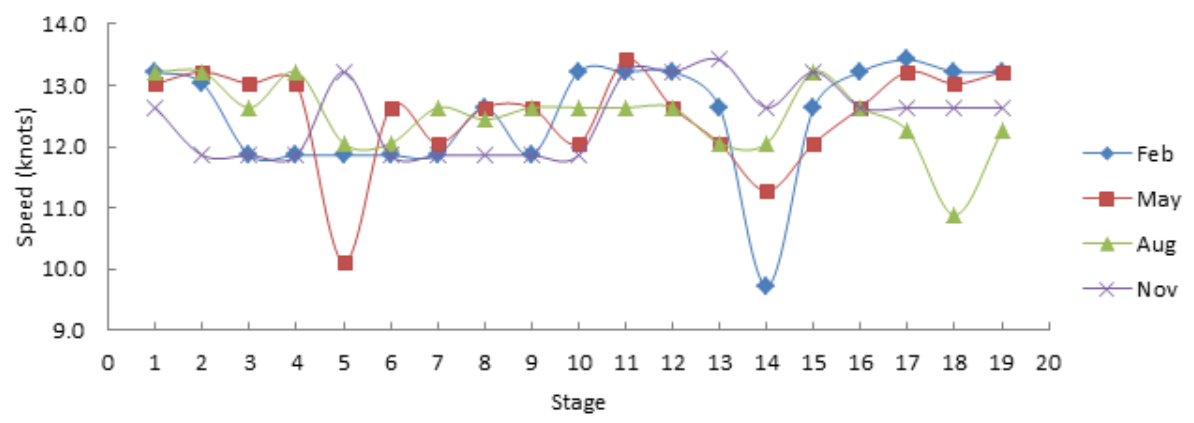

Fig. 6 Speed distribution based on different conditions for case study 2
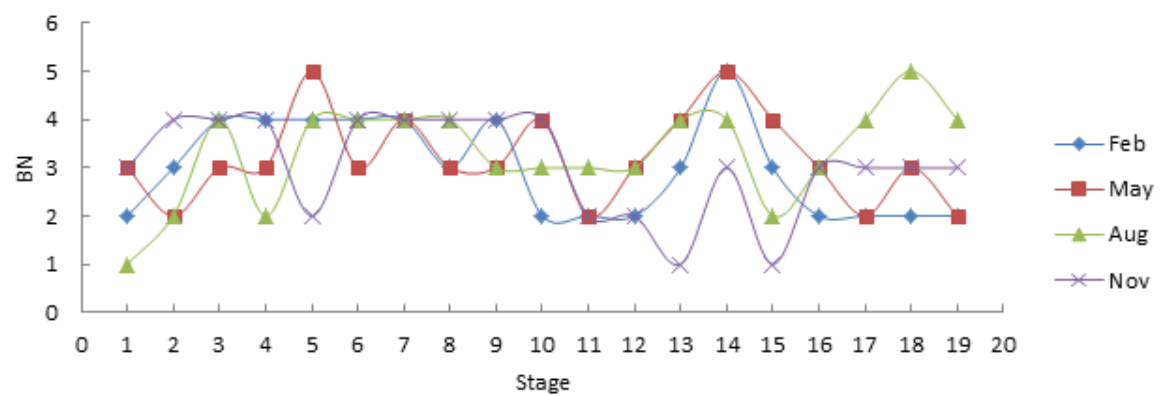

Fig. 7 BN distribution based on different conditions for case study 2

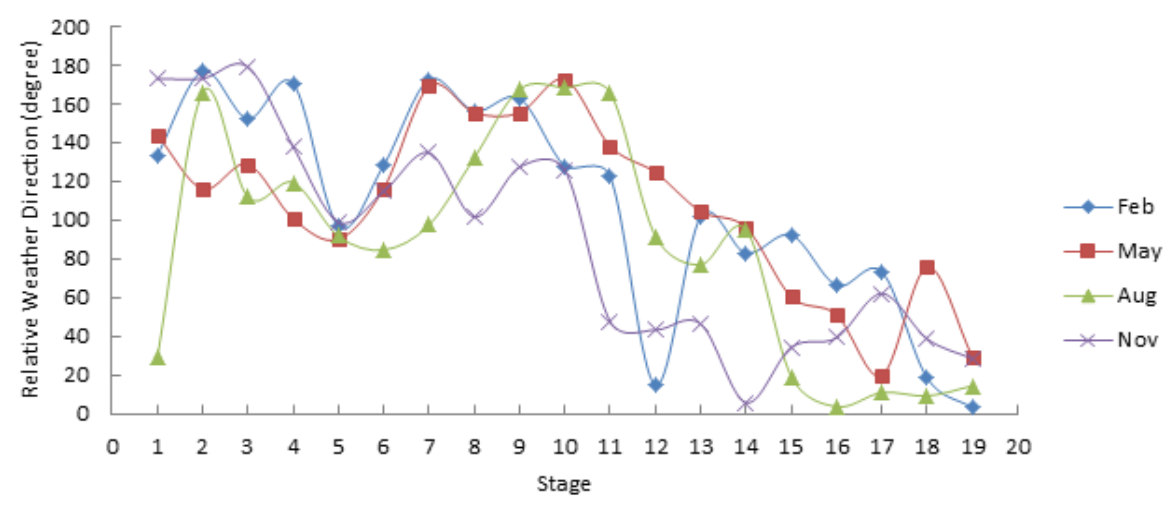

Fig. 8 Relative weather direction distribution based on different conditions for case study 2

The speed, BN and relative weather direction in each stage of all the Speed Set are extracted in Fig. 6, Fig. 7 and Fig. 8. As can be seen from these three figures, the ship speed still has very good response to different weather conditions, which proves the 
presented speed optimisation model works very well. Besides, all of these routes are drawn on the map in Fig. 9.

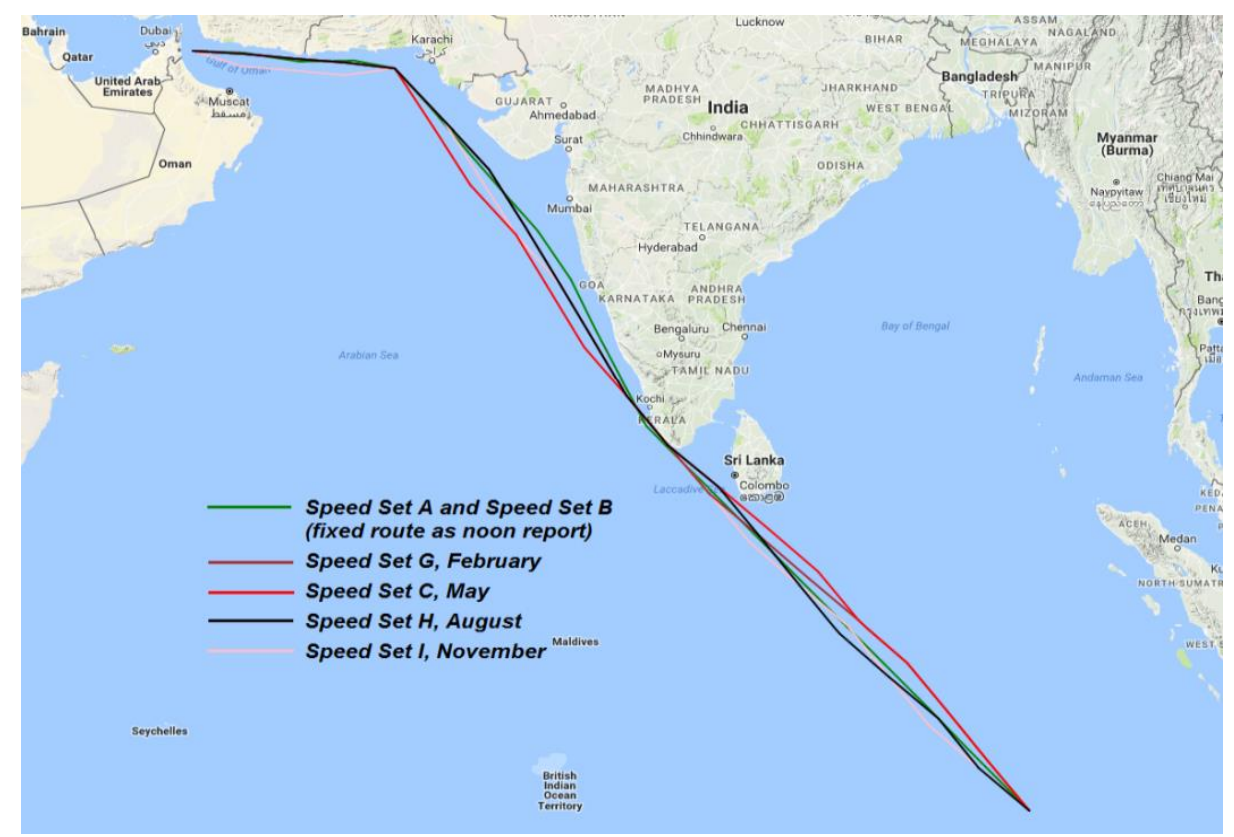

Fig. 9 Optimal routes based on different conditions for case study 2

\section{Conclusion}

This paper presents a speed optimisation model towards energy efficient shipping. With the integration of weather routing module, this model can provide stakeholders optimum ship operations in various weather conditions towards minimum fuel consumption according to the shipping schedule. Several case studies with Bulk Carrier were carried out. As can be seen from results, this model can help the case study shipping save almost $1.5 \%$ fuel consumptions, which proves the model works well.

Of course, during the speed optimisation process, there are always many uncertainties like the quality of ship performance prediction, weather forecasting limitations, service speed estimations or even operating profile of the engine etc, which always make the final result not reliable enough. In the future, the detailed research will be continued to improve this speed optimisation model further.

Finally, this model and the tool can be used towards: 1) Developing energy efficient ship operations strategies for shipping companies and can be used for fleet level optimisation. 2) Training crew to understand the effect of environ ment on ship energy performance and develop weather routing or voyage optimisation. 3) Assessment of various technologies and operational practices on ship performance for the individual voyage and annualis ed operations. 


\section{Acknowledgements}

This research is part of the project: Shipping in Changing Climates (EPSRC Grant no. $\mathrm{EP} / \mathrm{K} 039253 / 1)$. The author would like to express sincere thanks for the support from UK Research Council, University of Strathclyde and China Scholarship Council.

\section{Reference}

Buhaug $\varnothing$, Corbett JJ et al (2009). Prevention of air pollution from ships - second IMO GHG study, International Maritime Organization, London, UK.

Chen H, Cardone V and Lacey P (1998) Use of operation support information technology to increase ship safety and efficiency, SNAME transactions, 106, 105-127

Du Y, Chen Q, Quan X er al (2011) Berth allocation considering fuel consumption and vesselemissions. Trans portation Research 47E, 1021-1037

Golias M.M, Boile M, Theofanis S, Efstathiou C (2010) The berth scheduling problem: maximizing berth productivity and minimizing fuel consumption and emissions production. Transportation Research Record 2166, 20-27

HOLTROP J (1984) A Statistical Re-Analysis of Resistance and Propulsion Data. International Shipbuilding Progress, 31(363), 272-276

HOWETT B (2015) Report: SHIP PERFORMANCE PROFILE FILE FORMAT DEFINITION

IHS GLOBAL INSIGHT (2009) Valuation of the liner shipping industry-Economic contribution and liner industry operations

IMO (2012) Guidelines for the development of a SEEMP. MEPC 63/23, Annex 9

IMO (2014) Third IMO GHG Study 2014 - Exceutive Summary and Final Report

IMO (2016) Guidelines for the development of a SEEMP. MEPC 70/18/Add.1, Annex 10

Jussi P (2012) Overcoming the challenges in vessel speed optimization, HANSA International Maritime Journal, 149. Jahrgang - 2012 - Nr.9, 130-135

Kwon Y.J. (2008) Speed Loss Due To Added Resistance in Wind and Waves. The Naval Architect, Vol. 3, 14-16

Lang N, Veenstra A (2010) A quantitative analysis of container vessel arrival planning strategies. OR Spectrum 32, 477-499 
Lu R, Cui T, Turan O, Boulougouris E (2015) Speed management for energy efficient shipping, 2015 SCC Conference, UK

Norstad I, Fagerholt K, Laporte G (2011) Tramp ship routing and scheduling with speed optimization. Trans portation Research Part C: Emerging Technologies, 19, 853865

Oxford Economics (2014) The economic value of the EU shipping industry

Ronen D (2011) The effect of oil price on containership speed and fleet size. Journal of the Operational Research Society 62, 211-216

Simonsen MH, Larsson E, Mao W, Jonas W R (2015). State-of-the-art within ship weather routing. Proceedings of the ASME 34th International Conference on Ocean, Offshore and Arctic Engineering, St. John's, Newfoundland, Canada, OMAE

Wang S, Meng Q (2011) Schedule design and container routing in liner shipping. Transportation Research Record 2222, 25-33.

Wang S, Meng Q (2012) Liner ship fleet deployment with container transshipment operations, Transportation Research Part E 48, 470-484

Smith J, Jones M Jr, Houghton L et al (1999) Future of health insurance. N Engl J Med 965:325-329 